\title{
Tesis de Economía septiembre 1991-agosto 1992
}

\author{
Deparlamento de Economía \\ Universidad Centroamericana José Simeón Cafias
}

\section{El impacto de la política cambiaria en la determinación real del dólar y en el desequilibrio del sector externo período: junio 1989-diciembre 1990.}

Edmee Sahily Quintanilla Herrera René Orlando Quintanilla Romero Septiembre 1991 Nelson Arístides Rosa Escobar

Se realiza una evaluación de la política cambiaria en el periodo junio 1989-diciembre 1990. A manera de antecedenles, se plantea el papel de la política cambiaria en el modelo económico impulsado en el pais desde 1989 y se examina la evaluación de la política cambiaria en los años ochenta en sus diferentes aspeclos. Tomando, en cuenta los medios y los objelivos de la aclual polílica cambiaria respecto al sector exlerno, asi como el comportamiento del índice de tipo de cambio efectivo real y de las variables de las balanzas de pagos, se demueslra el reducido grado de electividad de la política cambiaria vigente. 


\section{¿Pequeña propledad o cooperativas de producción?: algunas recomendaciones para enfrentar el problema agrario salvadoreño}

Roxana Patricia Abrego Granados

Diciembre 1991

Marta Carolina Avalos Burgos

Nelly Jeanette Lardé Valladares

Definido el marco conceplual en cuanio al papel de la política agraria en el desarrollo económico, se analiza comparativamenle el comportamiento de las variables productividad, empleo e ingreso en el sector agropecuario reformado y no reformado en la década de los ochenta, explicando las causas de sus diferencias. Asimismo, se exponen las implicaciones de la actual política agraria sobre la productividad y el empleo en el seclor agropecuario. El estudio concluye que el problema agrario en el país no se enfrenla eficazmente promoviendo formas de propiedad -individual o colectiva - sino a partir de las modificaciones que se le hagan al enlorno económico y sociopolítico. Finalmente, se lormulan algunas recomendaciones para afrontar el problema agrario salvadorefio.

\section{Capacidad redistributiva de los salarios mínimos y estructura salarial en el sector agropecuario $1970-1990$}

José Víctor Aguilar Guillén

Diciembre 1991

Eugenio Callejas López

Carlos Antonio Rodriguez Torrento

Examinando algunos enfoques teóricos sobre los salarios mínimos y los criterios utilizados para su fijación en el pais, se analiza el comportamiento de los salarios mínimos en el sector agropecuario considerando la distribución funcional del ingreso, el proceso inllacionario y la evolución de las condiciones de vida de los trabajadores agropecuarios. Desde la concepción de los salarios minimos como un instrumenlo del desarrollo económico y social, se proponen ciertos lineamientos generales para que dichas remuneraciones ejerzan una función redistributivas en favor de los trabajadores del seclor agropecuario. 


\section{El deterioro del medio ambiente y su incidencia en la producción agroalimentaria de El Salvador}

Ana Lilian Vega Trejo

Marzo 1992

Leslie Quinónez Basagoitia

Se identifican y se analizan las causas de las diferentes manifestaciones del delerioro ambiental de mayores repercusiones en la producción agricola alimenlaria. También se estudia la evolución del deterioro ambiental y la producción agrícola alimentaria a lo largo del tiempo. El estudio evidencia de acuerdo con criterios más cuantitalivos que cualilativos el impacto de la degradación ambiental sobre la producción agroalimentaria del país.

\section{La ayuda alimentaria y su impacto en la seguridad allmentaria nacional durante la década de los años ochenta}

Gloria Miriam Rubio Santos

Marzo 1992

Juana Mabel Hernández

Planteado el marco conceptual de la seguridad alimentaria y esbozado el panorama mundial de la ayuda alimentaria, se analiza la ayuda alimentaria externa recibida por el país en los afios ochenta y su impaclo en la seguridad alimenlaria nacional. El esludio demuestra que si bien durante la década de los ochenta la asistencia alimentaria al pais registró niveles signiticativos, ésta no ha sido orientada directamente a salisfacer las necesidades alimentarias de la población. Se concluye que con la ayuda alimentaria exlerna se ha profundizado el fenómeno de la dependencia alimentaria, en deterioro de la seguridad alimentaria nacional. Finalmente, se vierten algunos elementos para la lormulación de una política de ayuda alimentaria que contribuya efeclivamente al logro de la autosuficiencia alimentaria en el pais. 


\title{
El nuevo orden mundial y la reinserción de El Salvador en la economia internacional
}

\author{
Carlos Umana Cerna
}

Marzo 1992

Partiendo de la caracterización de la tendencia del nuevo orden mundial y sus implicaciones para los paises subdesarrollados, se realiza un análisis de la evolución hislórica de la esluctura productiva nacional en el periodo 1948-1992 y de la política gubernamental vinculada al modelo económico vigenle en tal periodo identificando los condicionantes de la inserción del país a ese nuevo conlexto internacional. En oposición a los programas de ajuste estruclural, se formulan las bases para una política industrial orientada a la reestructuración productiva en el marco de un nuevo modelo de desarrollo socioeconómico.

\section{Opciones de la banca de fomento estatal para la democratización del crédito en El Salvador}

Carlos Portirio Martinez Castro

Marzo 1992

Eric Willredo Larreynaga Cruz

A partir de la esquematización de un modelo de Banca de Fomenlo para la economía del país y de un diagnóstico del desempeno de las instituciones que integran la Banca de Fomento en el pais, se evalúan tres alternalivas de Banca de Fomento para la democratización del crédito. Se concluye que la mejor allernaliva para lograr un proceso de democratización del crédilo en El Salvador consisle en la fusión de las tres inslituciones que inlegran la Banca de Fomento (BFA, FIGAPE, FEDECREDITO) para conformar una banca especializada en la micro y pequena empresa. 


\section{Las zonas francas en El Salvador: balance y perspectivas}

Irma Roxana Blanco

Mayo 1992

Se evalúa el desempeño de las zonas Irancas en el pais y su prospectiva. Bosquejado el marco conceptual acerca del papel de las zonas francas en la economía, se examina el desarrollo de la Zona Franca de San Bartolo en el periodo 1974-1991. El análisis comprende una evaluación de los resultados linancieros oblenidos y de los beneficios económicos generados, asi como de los laclores que incidieron en el desarrollo de la Zona. Sobre eslos elementos se formulan ciertas bases para el desarrollo de nuevas Zonas Francas en El Salvador. Asimismo, se sondean las perspeclivas de las nuevas Zonas Francas en el pais con respecto a otras Zonas Francas en el área Centroamericana.

\section{Competitividad Internacional: \\ hacia un proceso de reconversión industrial}

Ana Yolanda Morán Pineda

Linel Esperanza Contreras Trujillo

Junio 1992

Se evalúa la imporlancia y la capacidad competitiva inlernacional de la industria nacional. Se parte de una exposición de la evolución de la industria manufacturera en el pais y del marco conceptual referente a la reconversión industrial y compelilividad internacional. En base a indices cuantilativos, se demuestra que la industria salvadoref́a presenta un bajo grado de competitividad internacional. De ahi se sefhala la necesidad de replantear el programa de reconversión industrial en el actual contexto de liberalización del comercio exterior del pais. Finalmente, se establecen algunas consideraciones para que la reconversión industrial se base en la perspectiva del desarrollo económico en general. 


\section{Los impuestos sobre consumo de bebidas alcohólicas y alcohol etílico en El Salvador. Conveniencia de sustitución por impuestos selectivos de tipo ad-valorem}

José Emerson Manzano

Junio 1992

Sergio Javier Tamayo Ayala

Tomando como fundamenlo la leoría de la tribulación, el esludio comprende el análisis de los anlecedentes, caracteristicas de los impuestos al consumo de produclos alcohólicos y de su imporlancia en la estructura Iributaria en El Salvador. Se concluye que el actual lipo de impuesto al consumo de produclos alcohólicos presenta desde el punto de vista administrativo una eslructura deficienle que a su vez no permile al Eslado contar con un rendimiento fiscal viable, desde el punlo de vista económico. Considerando la necesidad de una relorma Iributaria y de las exlernalidades negalivas que ocasiona al consumo de productos alcohólicos, se propone la adopción del impueslo ad-valorem, eslablecidas sus ventajas con respeclo al actual impueslo selectivo.

\section{Análisis de la nueva ley orgánica del Banco Central de Reserva de El Salvador, y sus implicaciones en el sistema financiero nacional}

Se comienza exponiendo el marco conceplual de las funciones de la Banca Central, sus instrumenlos de política monetaria y linanciera, su importancia en el desarrollo económico y los lipos de sislemas linancieros, asi como la evolución histórica de la Banca Central en el pais antes de la nueva ley orgánica. El esludio se concentra en el análisis y la evaluación de la nueva ley orgánica del Banco Central de Reserva, destacando sus ventajas, desventajas y limitaciones en torno al cumplimiento de los objetivos esenciales de la Banca Central. Sobre tal base, se proponen una serie de relormas a la nueva ley orgánica del Banco Central de Reserva. 


\section{El papel de la integración regional para el desarrollo de El Salvador}

Edgar Antonio López

Julio 1992

Lorena María Calderón Eguizábal

Se exponen los antecedentes y la evolución reciente de la experiencia integracionista en Centro América en el actual contexto internacional como marco de referencia para el análisis del nuevo esquema de integración económica Centroamericana. Sobre tales bases se formulan ciertas propueslas para la reaclivación de la integración económica en Centroamérica, sefialando las venlajas y limilaciones del nuevo esquema y su significación en el desarrollo económico de los países del área.

\section{Aplicación del programa de ajuste estructural en Centro América y su relación con el proceso de integración económica}

Juan Anlonio Cortez Irahela

Agosto 1992

Ramona Mercedes Galán

Mario Ernesio Morán Zamora

A partir de una caraclerización general del curso trazado por el proceso de inlegración económica desde sus inicios hasla la presente década; se identitican las congruencias e incongruencias entre los programas de ajusle estructural en los países del área y el esquema de integración económica planteado en el Programa de Acción Económica para Centroamérica (PAECA). 